penicillamine and subsequently with gold to test this hypothesis.

We believe that the increased incidence of adverse reactions to D-penicillamine in patients with a history of gold toxicity is related to the short interval between the two treatments in many cases. Hence treatment with D-penicillamine in a patient who has reacted adversely to gold should probably be delayed for at least six months after gold, when the risk of further adverse reactions is apparently reduced.

\section{References}

${ }^{1}$ Huskisson EC, Gibson TJ, Balme HW, et al. Trial comparing Dpenicillamine and gold in rheumatoid arthritis. Ann Rheum Dis 1974 ; $33: 532-5$.
${ }^{2}$ Multicentre trial group. Controlled trial of D-penicillamine in severe rheumatoid arthritis. Lancet $1973 ; \mathrm{i}: 275-80$.

${ }^{3}$ Girdwood RH. Death after taking medicaments. Br Med f 1974; ; :501-4.

4 Day AT, Golding JR. Hazards of penicillamine therapy in the treatment of rheumatoid arthritis. Postgrad Med $\mathcal{F} 1974 ; 50$, suppl $2: 71-3$.

5 Webley M, Coomes EN. Is penicillamine therapy in rheumatoid arthritis influenced by previous treatment with gold? $B r$ Med 7 1978;ii:91.

${ }^{6}$ Multicentre trial group. Absence of toxic or therapeutic interaction between penicillamine and previously administered gold in a trial of penicillamine in rheumatoid disease. Postgrad Med $\mathcal{F} 1974 ; 50$, suppl 2: 77-8.

7 Walshe JM. Wilson's disease. New oral therapy. Lancet 1956;i :25-6.

8 Vernon-Roberts B, Dove JL, Jessop JD, Henderson WJ. Selective concentration and localisation of gold in macrophages of synovial and other tissues during and after chrysotherapy in rheumatoid patients. Ann Rheum Dis 1976;35:477-86.

(Accepted 18 March 1980)

\title{
Insulin-induced lipoatrophy: evidence for an immune pathogenesis
}

\author{
W G REEVES， B R ALLEN， R B TATTERSALL
}

\section{Summary and conclusions}

Skin biopsy samples from 14 diabetic patients with lipoatrophy at injection sites and from five insulintreated diabetic patients without such lipoatrophy (controls) were examined by immunofluorescence for the deposition of immunological components. Also sera from 13 of the patients with lipoatrophy and from all of the controls were assayed for insulin-binding capacity.

Biopsy samples from the edge of lipoatrophic areas (eight cases) invariably showed abnormal deposition of immunological components in dermal vessel walls, whereas no such deposition was seen in the control samples. Mean serum insulin-binding capacity was $33 \cdot 1$ $\mu \mathrm{g} / \mathrm{l}$ in the patients with lipoatrophy compared with only $4.6 \mu \mathrm{g} / 1$ in the controls.

These findings suggest that insulin-induced lipoatrophy results from the local formation of immune complexes, complement fixation, and release of inflammatory mediators from the cellular infiltrate.

\section{Introduction}

Lipoatrophy at injection sites is a common complication of treatment with insulin and has been reported in $10 \%, 124 \%$, and $55 \%^{3}$ of patients treated with conventional bovine insulins. Many theories have been proposed, but the exact pathogenesis remains obscure. Lipoatrophy is almost unknown in patients treated only with highly purified porcine insulins, ${ }^{14}$ which prompted us to examine the role of immunological factors in its pathogenesis.

\section{Patients and methods}

We studied one man and 13 women with moderate or severe lipoatrophy. Their mean age was 45 years (range 15-74) and the mean

University Hospital, Nottingham NG7 2UH

W G REEVES, BSC, FRCP, consultant immunologist and senior lecturer B R ALLEN, MB, MRCP, consultant dermatologist R B TATTERSALL, MD, MRCP, consultant physician duration of treatment with insulin 11 years (range four months to 30 years). Five insulin-treated patients (three women and two men) without evidence of lipoatrophy served as controls; they were younger than the study group (mean age 25 years) but had been treated with insulin for a similar time (mean 10 years) (see table I). Figure 1 shows the clinical appearance of the lipoatrophy in case 1 .

TABLE I-Sex, age, serum insulin binding capacity (IBC), and details of treatment with insulin in 14 patients with lipoatrophy and in five control patients

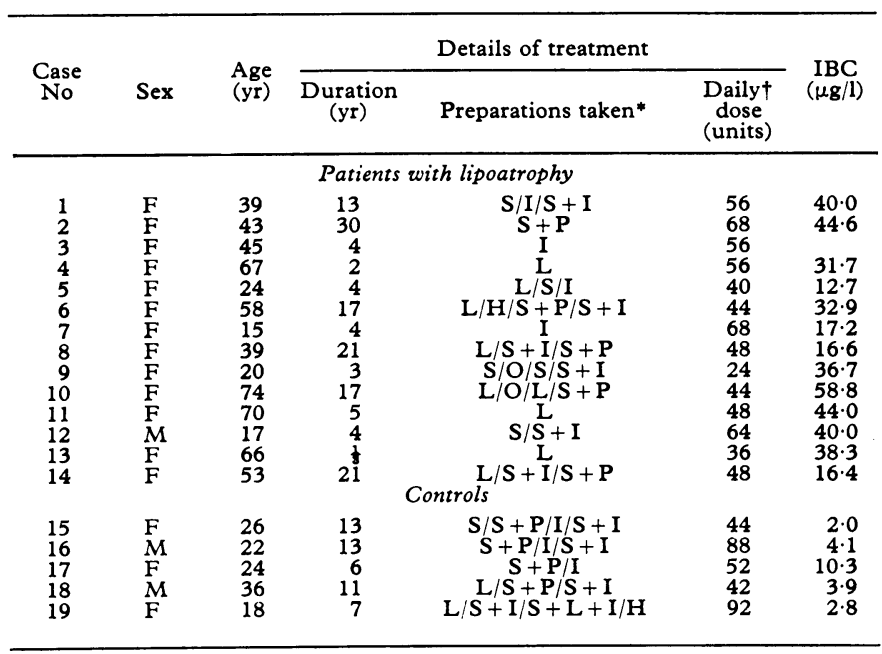

* $/=$ Change to different regimen. $+=$ Preparations taken together. $S=$ Soluble $\mathrm{I}=$ Isophane. $\mathrm{P}=$ Protamine zinc. $\mathrm{L}=$ Lente. $\mathrm{H}=$ Highly purified. $\mathrm{O}=$ Oral hypoglycaemic agents.

Skin biopsy samples were taken from the edge of lipoatrophic areas in eight patients (cases 1-8), from the middle of lipoatrophic areas in three (cases 9-11), and from normal skin distant to injection sites in three (cases 12-14). The five control biopsy samples were taken from non-lipoatrophic areas that had recently been repeatedly injected with insulin. Biopsy tissue was snap-frozen in liquid nitrogen. Immunofluorescence analysis was performed as described. ${ }^{5}$ Cryostat sections were incubated with fluorescein-conjugated antisera specific for IgG, IgA, IgM, C1q, C3, and fibrin-fibrinogen (Dako Immunoglobulins Ltd). Sections were examined in both blue and ultraviolet light with a Leitz Ortholux incident light microscopy system. Insulin was 
detected with an indirect immunofluorescence technique in which sections were initially incubated with unconjugated guinea-pig antiinsulin serum followed by fluorescein-conjugated anti-guinea-pig immunoglobulin serum (both from Wellcome Reagents Ltd). Normal guinea-pig serum was used as a control in the first stage of this assay. The degree of deposition of immunological components was scored as absent $(-)$ or present $(+,++$, or +++$)$.

Thirteen of the 14 patients with lipoatrophy had blood taken at the time of biopsy. Serum insulin-binding capacity was assayed by a second antibody coprecipitation assay specific for IgG antibody. ${ }^{\circ}$ Results are expressed in $\mu \mathrm{g} / \mathrm{l}$. For comparison we also included measurements of insulin-binding capacity from three other groups of patients: 17 newly diagnosed diabetics before treatment with insulin, 29 patients who had taken bovine soluble and isophane insulins for at least three years without developing lipoatrophy or insulin resistance, and 16 patients with insulin resistance (arbitrarily defined as taking over 120 units daily) (see fig 2).

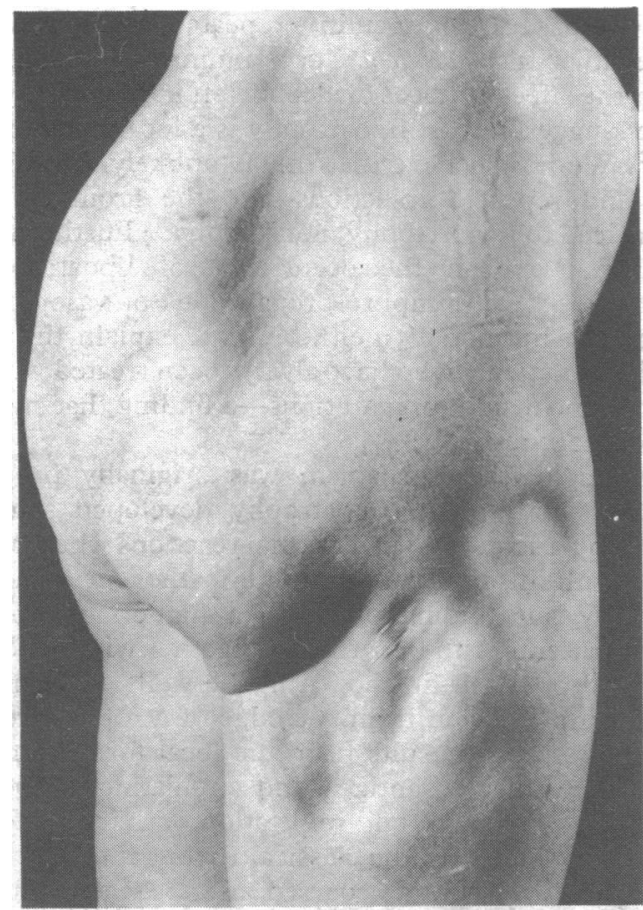

FIG 1-Case 1. Woman aged 39. Appearance of lipoatrophy at injection sites.

\section{Results}

There was wide variation in the types of insulin used by the patients with lipoatrophy (table I). Five had been treated with only one type of insulin (lente in three and isophane in two). Two patients (cases 9 and 10) had had a break in insulin treatment. Four of the controls had always taken bovine insulins, and three were taking twice-daily soluble and isophane insulins at the time of biopsy. One patient (case 19) had been taking highly purified insulin (Actrapid and Leo-Retard) for a year before biopsy.

The mean serum insulin-binding capacity in 13 of the patients with lipoatrophy (group B; fig 2) was $33.1 \mu \mathrm{g} / \mathrm{l}$, which was much higher than that in the five control patients who underwent skin biopsy $(4.6 \mu \mathrm{g} / 1)$. Furthermore, the insulin-binding capacity in 29 patients who had received bovine insulin for at least three years without experiencing lipoatrophy or insulin resistance rarely exceeded $20 \mu \mathrm{g} / \mathrm{l}$ (group C; fig 2), with no significant difference in values between the sexes. Patients with insulin resistance (group A) had values even higher than those in patients with lipoatrophy.

Immunofluorescence examination of biopsy samples from the edge of lipoatrophic areas showed abnormal deposition of immunological components in dermal blood vessels in all eight cases examined (fig 3; table II). The most consistent finding was deposition of IgM with $\mathrm{C} 3$ or fibrin-fibrinogen, or both. IgA was also seen in dermal blood vessel walls in samples from two patients (cases 1 and 2). All biopsy samples from lipoatrophic areas and from injection sites in controls contained diffuse IgG throughout the dermis, obscuring any specific localisation to blood vessel walls. Diffuse dermal IgG is often detected in skin biopsy samples examined by immunofluorescence. This does not necessarily indicate pathological change or correlate with the serum IgG concentration (WG Reeves, unpublished observations, 1979). Five samples from the edge of lipoatrophic areas also showed mild granular deposition of immunological components (IgM, IgA, $\mathrm{C} 3$, or fibrin-fibrinogen) at the dermoepidermal junction.

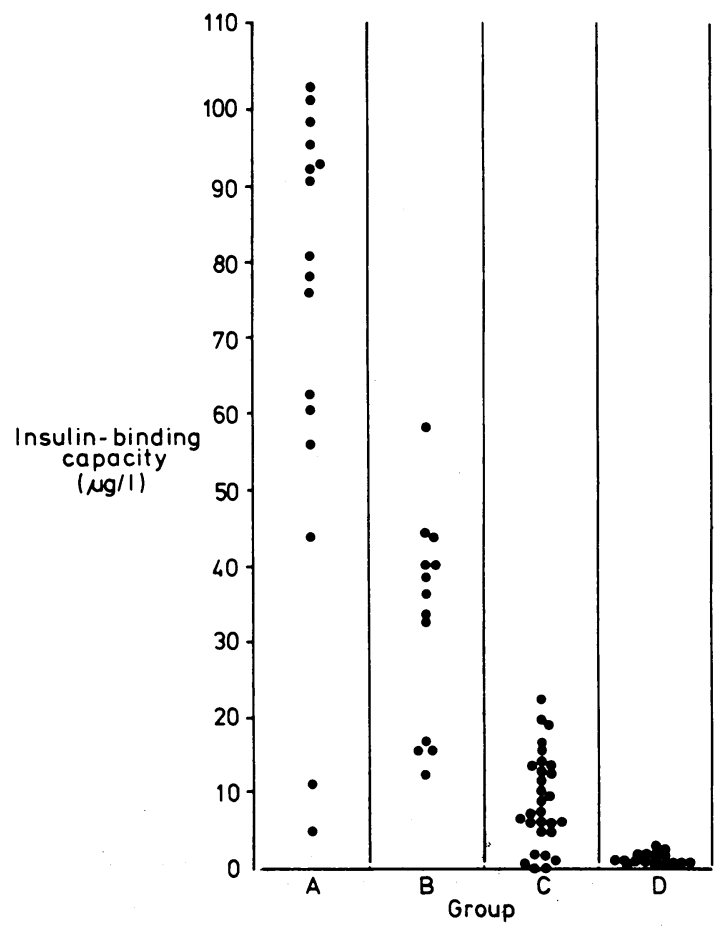

FIG 2-Insulin-binding capacity of sera in four groups of diabetic patients. Group $\mathrm{A}=$ Patients with resistance to insulin (daily dose over 120 units). Group $\mathrm{B}=$ Patients with lipoatrophy. Group $\mathrm{C}=$ Patients who had taken soluble and isophane insulins for at least three years without developing lipoatrophy or resistance to insulin. Group $\mathrm{D}=$ Newly diagnosed diabetic patients before treatment with insulin.

TABLE II-Dermal blood vessel deposition of immunological components in biopsy samples taken from edge of lipoatrophic area in eight patients and from injection sites in five control patients

\begin{tabular}{cccc}
$\begin{array}{c}\text { Case } \\
\text { No }\end{array}$ & IgM & C3 & $\begin{array}{c}\text { Fibrin- } \\
\text { fibrinogen }\end{array}$ \\
\hline \multicolumn{5}{c}{$\begin{array}{c}\text { Patients with lipoatrophy } \\
1\end{array}$} & +++ & ++ & + \\
2 & + & ++ & + \\
3 & + & + & - \\
4 & + & + & - \\
5 & + & - & ++ \\
6 & + & - & + \\
7 & + & - & + \\
8 & + & - & - \\
15 & - & - & - \\
16 & - & - & - \\
17 & - & - & - \\
18 & - & - & - \\
19 & - & - & - \\
\hline
\end{tabular}

The changes were much less pronounced in the biopsy samples from the middle of the lipoatrophic areas (in three patients). Examination showed mild $(+)$ deposition of fibrinogen in all samples and mild $(t)$ deposition of $\operatorname{IgM}$ in one. Immunofluorescence examination of normal skin from each of the three patients showed no deposition of immunological components in dermal blood vessels or at the dermoepidermal junction. Similar findings were obtained in the samples from injection sites in the five patients without lipoatrophy. 
In one patient (case 2 ; table I) crystals were seen in the deeper part of the dermis on direct immunofluorescence examination. On indirect examination these crystals were shown to react with an anti-insulin serum (fig 4).

Conventional histological examination of five biopsy samples from lipoatrophic sites showed variable but mild perivascular infiltration of mononuclear cells into the upper dermis. Fat atrophy was present in

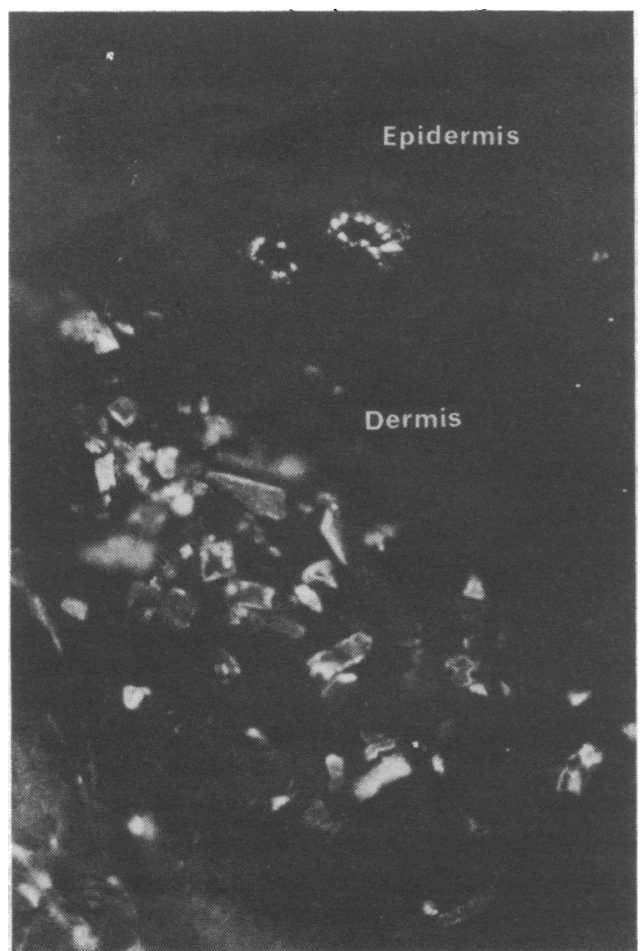

FIG 3-Case 2. Deposition of C3 in vessel walls in superficial dermis and presence of crystals in deeper dermis in biopsy sample from edge of lipoatrophic area, shown by direct immunofluorescence technique.

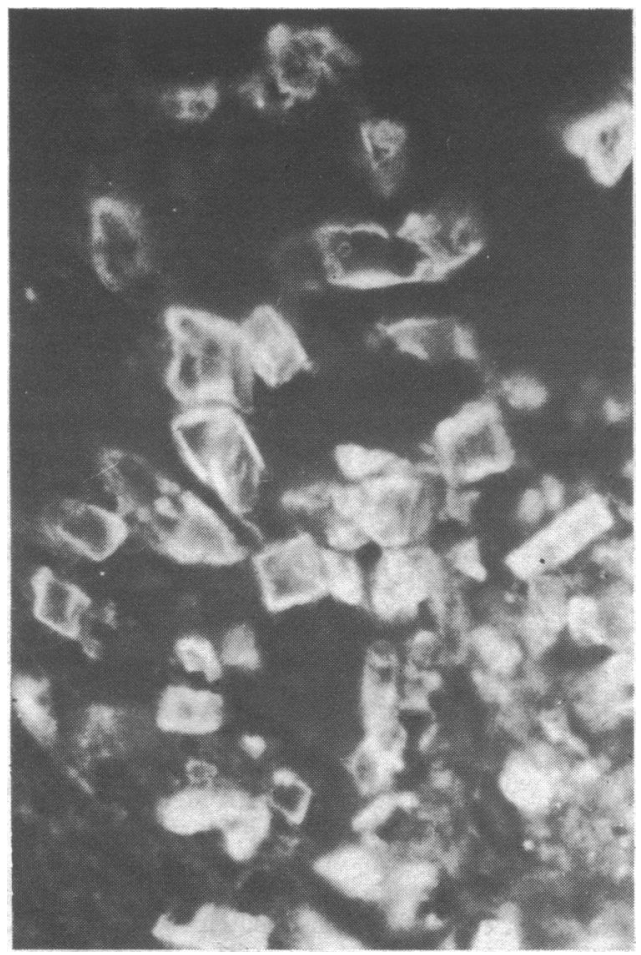

FIG 4-Case 2. Reaction of crystals in dermis with anti-insulin serum, shown by indirect immunofluorescence technique. the deeper dermis. Pigment-containing macrophages were often present, and iron was detected in deeper layers of the dermis. Examination of biopsy samples from the injection sites in two patients without lipoatrophy also showed mild perivascular infiltration, although the cells were predominantly polymorphonuclear (neutrophils and eosinophils) and often found in association with plasma cells.

\section{Discussion}

With the exception of hypoglycaemia, atrophy of subcutaneous fat at injection sites is the commonest complication of treatment with insulin. The observed incidence depends largely on the group studied, since lipoatrophy is thought to be commoner in younger patients and women. ${ }^{78}$ In susceptible people atrophy develops relatively soon after starting insulin: a mean of 269 days was recorded in Paley's series. ${ }^{3}$

The pathogenesis of lipoatrophy has never been satisfactorily explained. Proposed mechanisms include the presence of minute amounts of lipase in the insulin, ${ }^{9}$ repeated mechanical trauma from the injecting needle, ${ }^{10}$ cryotrauma from refrigerated insulin, or the effect of traces of alcohol left in reusable syringes.11

Marble ${ }^{7}$ suggested that lipoatrophy is a local metabolic effect of insulin. We now believe that this is unlikely. Insulin is not lipolytic, and repeated injections into the groin fat pads of female rats lead to hypertrophy, not atrophy..$^{12}$ Furthermore, this theory cannot explain the occurrence of lipoatrophy after injections of relatively impure preparations of vasopressin ${ }^{13}$ or human growth hormone ${ }^{14}$; neither can it explain the rarity of lipoatrophy in patients who have always been treated with highly. purified porcine insulin preparations-a finding that suggests an immune pathogenesis.

An immunological mechanism was originally proposed by Paley, ${ }^{3}$ who showed that lipoatrophy developed significantly more often in patients who had dermal reactions when beginning treatment with insulin. An immune pathogenesis is further supported by our finding of a much higher insulin-binding capacity in patients with lipoatrophy together with deposition of IgM with C3 or fibrin-fibrinogen in the walls of dermal blood vessels in samples taken from the edge of atrophic areas. This suggests that atrophy results from the local formation of complexes between injected antigen and circulating antibody with activation of complement and infiltration of inflammatory cells. This is broadly similar to the classical Arthus reaction, in which a localised acute vasculitis occurred after repeated injection of horse serum into rabbit skin. ${ }^{15} 16$ More recent studies have detected the appearance of antigen, antibody, and complement in local blood vessel walls. ${ }^{17}$ Experimental Arthus reactions usually reach a peak in intensity between six and 12 hours after injection of the antigen, when the infiltrate is mostly polymorphonuclear. Mononuclear cells, however, predominate during the succeeding 24-48 hours. ${ }^{17}$

Although patients may describe transient red nodules or urticarial lesions soon after beginning insulin injections, the clinical appearance of lipoatrophy is notable for its lack of inflammatory features. This contrast with the Arthus reaction is probably due to the considerable difference in antigenicity between whole horse serum and recrystallised insulin preparations, and to the different dose and frequency of injections. The improvement observed when steroid (dexamethasone) is combined with the insulin injection ${ }^{11}$ is in keeping with immunecomplex-mediated tissue damage. The minor changes seen in biopsy samples from the middle of lipoatrophic areas emphasise the importance of taking samples from the edge of lesions to obtain positive immunofluorescence findings.

Lipoatrophy occurs in patients who have been treated only with soluble insulin but is generally believed to be at least twice as common in patients taking modified insulins of medium or long duration. ${ }^{2}$ These forms of insulin persist at the injection site longer and provide a ready source of local antigen. Immunofluorescence studies on one of our patients being treated with protamine zinc insulin showed that entire crystals may be 
present in the dermis (fig 4). The increased zinc concentration in lente and protamine zinc preparations or the presence of fish protamine in isophane and protamine zinc insulins may enhance the immunological response to injected insulin. ${ }^{18}$ The remarkable female preponderance in this and other series of patients with lipoatrophy is difficult to explain immunologically. Lipoatrophy may be more obvious in women, in whom there is more subcutaneous tissue available for dramatic change.

Lipoatrophy at sites remote from injection, such as the breasts and face, has occasionally been reported and is difficult to explain by any theory of insulin-induced lipoatrophy. We think it much more likely that if such cases occur they represent the coexistence of insulin-dependent diabetes with some other form of lipodystrophy. ${ }^{19} 20$

We thank the many colleagues who have helped in collecting appropriate skin biopsy and blood specimens, the technical staff of the immunology department for their skilled help in preparing material for immunofluorescence and performing the insulin-binding capacity assays, Alasdair Mackay for reviewing the histological findings, and Anne Willington for typing the manuscript. The insulin-binding capacity assay was developed during tenure of a research grant from the British Diabetic Association. The valuable help of Novo Laboratories Ltd is also gratefully acknowledged.

Requests for reprints should be addressed to Dr W G Reeves.

\section{References}

${ }^{1}$ Wright $\mathrm{AD}$, Walsh $\mathrm{CH}$, Fitzgerald MG, Malins JM. Very pure porcine insulin in clinical practice. $B r$ Med $\mathcal{f} 1979 ; \mathrm{i}: 25-7$.

2 Renold AE, Winegrad AI, Martins DB. Diabete sucré et tissue adipeux. Helvetica Medica Acta 1957;24:322-7.

3 Paley RG. Lipodystrophy following insulin injections. Metabolism 1953;2: 201-10.
${ }^{4}$ Poulsen JE, Deckert T. Insulin preparations and the clinical use of insulin. Acta Med Scand [Suppl] 1976;601:197-245.

5 Marriott DW, Reeves WG. Immunofluorescence. In: Bancroft JD, Stevens A, eds. Theory and practice of histological techniques. Edinburgh: Churchill Livingstone, 1977:387-93.

- Reeves WG, Kelly U. An immunochemical method for the quantitation of insulin antibodies. $f$ Immunol Methods (in press).

${ }^{7}$ Marble A. In: Ellenberg M, Rifkin $\mathrm{H}$, eds. Diabetes mellitus: theory and practice. New York: McGraw Hill, 1970:638.

8. Watson D, Vines R. Variations in the incidence of lipodystrophy using different insulins. Med $\mathcal{F}$ Aust 1973; : 248-50.

- Carmichael EA, Graham G. Local fat atrophy following insulin injections. Lancet $1928 ; \mathrm{i}: 601$.

${ }^{10}$ Avery $\mathrm{H}$. Insulin fat atrophy: a traumatic atrophic panniculitis. $\mathrm{Br} \mathrm{Med} \mathcal{F}$ $1929 ; \mathrm{i}: 597$.

11 Kumar D, Miller LV, Mehtalia SD. Use of dexamethasone in treatment of insulin lipoatrophy. Diabetes $1977 ; 26: 296-9$.

12 Renold AE, Marble A, Fawcett DW. Action of insulin on deposition of glycogen and storage of fat in sub-cutaneous tissue. Endocrinology 1950 $46: 55$.

${ }^{13}$ Malins JM. Clinical diabetes mellitus. London: Eyre and Spottiswoode, $1968: 408$.

${ }^{14}$ Underwood LE, Voina SJ, Vanwyk JJ. Restoration of growth by human growth hormone (ROOS) in hypopituitary dwarfs immunized by othe human growth hormone preparations: clinical and immunological studies. F Clin Endocrinol Metab 1974;38:288-97.

${ }^{15}$ Arthus $M$. Injections répétées de sérum de cheval chez le lapin. Comptes Rendue Societé Biologie (Paris) 1903;55:817-20.

${ }^{16}$ Arthus $M$, Breton. M. Lésions cutanées produites par les injections de sérum de cheval chez le lapin anaphylactisé par et pour se sérum. Comptes Rendue Societé Biologie (Paris) $1903 ; 55: 1478-80$.

17 Cochrane G, Dixon FJ. Immune complex injury. In: Samter M, ed. Immunological diseases. Boston: Little Brown, 1978:210-29.

${ }^{18}$ Reeves WG. Immunology of diabetes and insulin therapy. Recent Advances in Clinical Immunology (in press).

${ }^{19}$ Crome P, Keen H. Partial lipodystrophy and insulin-resistant diabetes. Diabete Metab 1978;4:81-4.

${ }^{20}$ Kodama S, Kasuga M, Seki A, et al. Congenital generalized lipodystrophy with insulin-resistant diabetes. Eur $\mathcal{F}$ Pediatr 1978;127:111-9.

(Accepted 31 March 1980)

\footnotetext{
Departments of Surgery and Physiotherapy, Bristol Royal Infirmary, Bristol BS2 8HW

P C CLIFFORD, FRCS, British Heart Foundation research fellow $P$ W DAVIES, MIBIOL, chief technician

JULIET A HAYNE, MCSP, senior physiotherapist

R N BAIRD, CHM, FRCS, consultant senior lecturer in surgery
}

also felt much healthier, having unduly restricted their activities before because they had feared the onset of ischaemic leg pain.

These results suggest that supervised exercise training is a simple and effective method of treating patients with intermittent claudication.

\section{Introduction}

The beneficial effects of daily walks and physical training in intermittent claudication were first described by Foley ${ }^{1}$ and confirmed by American ${ }^{2}$ and Scandinavian ${ }^{3-6}$ reports. The traditional view is that sufferers should slow down, stop smoking, and hope for the best. ${ }^{7}$ Patients with intermittent claudication tend to eschew physical exercise since they fear the onset of ischaemic leg pain. Nevertheless, they also risk becoming completely housebound or dependent on the car. Those attending hospital outpatient clinics have usually already been given at least one vasodilator drug without success, and most, who are not offered arterial reconstruction, look to the vascular surgeon for effective medical treatment. We have evaluated the usefulness of an exercise class for patients with intermittent claudication. 